\title{
Marie Blain-Pinel, La Mer, miroir d'infini. La métaphore marine dans la poésie romantique
}

\section{Elettra Bordino Zorzi}

\section{(2) OpenEdition}

1 Journals

\section{Édition électronique}

URL : http://journals.openedition.org/studifrancesi/36306

DOI : 10.4000/studifrancesi.36306

ISSN : 2421-5856

Éditeur

Rosenberg \& Sellier

\section{Édition imprimée}

Date de publication : 1 juillet 2005

Pagination : 176-177

ISSN : 0039-2944

\section{Référence électronique}

Elettra Bordino Zorzi, « Marie Blain-Pinel, La Mer, miroir d'infini. La métaphore marine dans la poésie romantique », Studi Francesi [En ligne], 145 (XLIX | I) | 2005, mis en ligne le 30 novembre 2015, consulté le 18 avril 2021. URL : http://journals.openedition.org/studifrancesi/36306 ; DOI : https://doi.org/ 10.4000/studifrancesi.36306

Ce document a été généré automatiquement le 18 avril 2021.

\section{(c)}

Studi Francesi è distribuita con Licenza Creative Commons Attribuzione - Non commerciale - Non opere derivate 4.0 Internazionale. 


\title{
Marie Blain-Pinel, La Mer, miroir d'infini. La métaphore marine dans la poésie romantique
}

\author{
Elettra Bordino Zorzi
}

\section{RÉFÉRENCE}

MARIE BLAIN-PINEL, La Mer, miroir d'infini. La métaphore marine dans la poésie romantique, Rennes, Presses universitaires de Rennes, 2003 («Interférences»), pp. 313.

1 Point d'articulation et de rayonnement d'une pensée qui se veut analogique, l'image de la mer suscite dans la poésie romantique des échos multiples et différents. Si la tradition littéraire précédente la relie au topos de la tempête et du déluge, car elle apparaît comme le lieu de manifestation de l'aspect le plus terrible et vindicatif de la divinité, à partir de Chateaubriand les clichés classiques et judéo-chrétiens cèdent peu à peu le pas à une vision plus moderne qui, en dévoilant des côtés nouveaux de l'élément marin, alimente une quête ontologique à laquelle s'associe indissolublement le sentiment du sacré.

2 Suivant une méthode critique clairement énoncée, que viennent étayer les affirmations de G. Bachelard, de M. Collot, de P. Ricœur, Marie Blain-Pinel s'attache à analyser la métaphore marine dans toute la complexité qu'elle acquiert à l'intérieur de la poésie romantique. Dotée à la fois d'un fond archétypal, d'une matrice descriptive et d'une visée heuristique, celle-ci se donne non seulement pour une figure de sens porteuse d'une innovation sémantique, mais aussi pour une structure s'appliquant à la phrase et s'étendant ensuite à l'œuvre entière.

3 Après les contre-exemples de Chénier, chez qui le recours massif au stéréotype empêche toute véritable originalité, et de Lamartine, dont les nombreuses références à la mer n'arrivent pas à former un réseau d'images cohérent et personnel, c'est dans les 
cinq auteurs suivants que ce trope va manifester toutes ses potentialités: Vigny, SainteBeuve, Quinet, Hugo et Baudelaire.

4 Signe de la puissance aveugle de Dieu, à laquelle l'homme se doit d'échapper par la voie de l'intellectualisation, dans les poèmes de Vigny la mer perd progressivement sa substance matérielle pour ne devenir qu'un support iconique de la réflexion philosophique. Chez Sainte-Beuve, en revanche, le flux et reflux des vagues traduit dans un registre concret les hésitations existentielles de l'écrivain, perpétuellement écartelé entre la furie des passions et l'aspiration au calme, à ce dépassement de soi que pourrait offrir la création poétique ou une foi vraiment solide. L'Ahasvérus d'Edgar Quinet assigne à l'Océan une vocation encore différente: personnifié, il acquiert une épaisseur à la fois lyrique et épique dans la mesure où, en tant que figure non pas du Père mais du Christ, il incarne l'humanité souffrante à la recherche de l'Infini. Le mélange des genres se retrouve chez Hugo, à qui le motif maritime inspire en même temps de l'inquiétude et de la fascination. $\mathrm{Si}$, en fait, il raconte la lutte dramatique mais héroïque que l'homme engage contre la mer pour en dominer la force destructrice, d'autre part, dans les quelques moments de bonace, son chant s'élève en guise de prière pour célébrer l'amour divin. Grâce à sa puissante imagination matérielle, l'immensité océane devient ainsi un symbole de la transcendance, ce qui constitue le trait d'union avec Baudelaire. Malgré l'idée splénétique que l'Absolu reste toujours hors d'atteinte, ce dernier considère en effet l'univers marin comme une voie privilégiée d'accès à l'Idéal car, par le biais d'un traitement oxymorique de la métaphore, selon lequel la sensualité des synesthésies se mêle à la tension métaphysique du symbole, celui-ci se fait le miroir de l'inconnu insaisissable, en cela double parfait de la femme et, surtout, de l'écriture poétique.

Mais, depuis 1860, la métaphore marine voit son rayon d'action se rétrécir, car elle perd son rôle de catalyseur et de producteur du sens. Les responsables de cet appauvrissement sont non seulement le scientisme de Michelet, avec son regard laïque, mais aussi les deux nouvelles écoles esthétiques du siècle, qui aboutissent par des voies opposées au même résultat d'estompe. En effet, alors que le Parnasse renie les épanchements de la subjectivité au nom d'une impassibilité qui finit par rejoindre la conception scientiste, le symbolisme renonce au contact référentiel en vertu d'un idéalisme dont est toutefois exclue la richesse concrète du motif maritime.

Pour entendre encore résonner les notes pleines et mystérieuses de la mer cosmique et sacrée, il faut attendre les ouvrages de Claudel et de Saint-John Perse qui, chacun à sa manière, prolongent au $\mathrm{XX}^{\mathrm{e}}$ siècle la navigation plurivoque inaugurée par leurs ancêtres romantiques. 